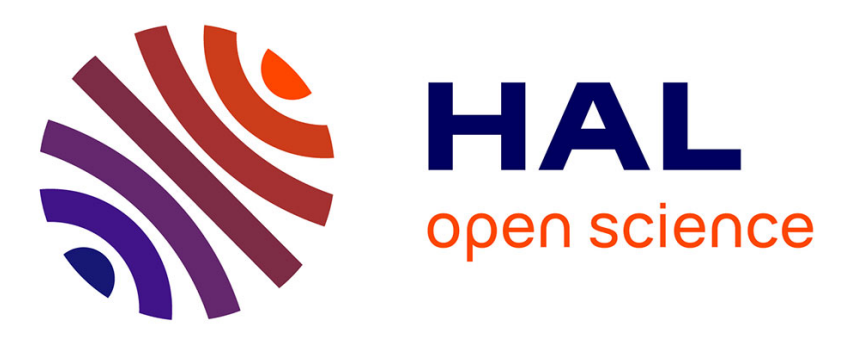

\title{
Natural convection in shear-thinning fluids: Experimental investigations by MRI
}

Mohamed Darbouli, Christel Métivier, Sébastien Leclerc, Chérif Nouar, Mondher Bouteera, Didier Stemmelen

\section{- To cite this version:}

Mohamed Darbouli, Christel Métivier, Sébastien Leclerc, Chérif Nouar, Mondher Bouteera, et al.. Natural convection in shear-thinning fluids: Experimental investigations by MRI. International Journal of Heat and Mass Transfer, 2016, 95, pp.742-754. 10.1016/j.ijheatmasstransfer.2015.12.056 . hal01408983

\section{HAL Id: hal-01408983 \\ https://hal.univ-lorraine.fr/hal-01408983}

Submitted on 20 Jan 2017

HAL is a multi-disciplinary open access archive for the deposit and dissemination of scientific research documents, whether they are published or not. The documents may come from teaching and research institutions in France or abroad, or from public or private research centers.
L'archive ouverte pluridisciplinaire HAL, est destinée au dépôt et à la diffusion de documents scientifiques de niveau recherche, publiés ou non, émanant des établissements d'enseignement et de recherche français ou étrangers, des laboratoires publics ou privés. 


\title{
Natural convection in shear-thinning fluids: experimental investigations by MRI
}

\author{
Mohamed Darbouli ${ }^{\mathrm{a}}$, Christel Métivier ${ }^{\mathrm{a}, *}$, Sébastien Leclerc ${ }^{\mathrm{a}}$, Chérif Nouar ${ }^{\mathrm{a}}$, \\ Mondher Bouteera $^{\mathrm{a}}$, Didier Stemmelen ${ }^{\mathrm{a}}$ \\ ${ }^{a}$ Laboratoire d'Energétique et de Mécanique Théorique et Appliquée, UMR 7563 (Université \\ de Lorraine, $C N R S)$, France
}

\begin{abstract}
An experimental investigation of the Rayleigh-Bénard convection in shear-thinning fluids is presented by using MRI technics. The experimental setup consists on a cylindrical cavity defined by a finite aspect ratio $A=D / d=6$. Qualitative and quantitative results are provided. Flow visualizations are presented via velocity mapping for a Newtonian fluid, the Glycerol and for shear-thinning fluids, Xanthan gum aqueous solutions with weight concentrations ranging from 0.1 to $0.2 \%$. In the case of the Glycerol and the Xanthan solution at $0.1 \%$, one recovers similar results in terms of criticality with $R a_{c}=1800$ and patterns since the convection is characterized by rolls. When the Xanthan concentration is increased, the critical Rayleigh number is not modified, however the onset occurs with hexagonal pattern. Because the critical temperature differences increase with the concentrations due to an increase in viscosity, hexagonal patterns are due to variations of physical properties with temperature (non Oberbeck-Boussinesq effects). Similarities with some results obtained in the Newtonian case are highlighted. We have observed a transition from hexagonal patterns to rolls by increasing the Rayleigh number. This pattern transition is characterized by a discrepancy in the maximal velocity values. By using shearthinning fluids, results show an increase in the intensity of convection compared with the Newtonian case.
\end{abstract}

Keywords: shear-thinning fluids; Rayleigh-Bénard convection ; MRI; NMR velocity mapping; non Boussinesq effects.

\section{Introduction}

The Rayleigh-Bénard instability is a buoyancy driven motion in a fluid layer confined between two horizontal walls separated by $d$. The Rayleigh-Bénard Convection (RBC) in Newtonian fluids has been extensively studied since more

\footnotetext{
*. Corresponding author

Email address: Christel.Metivier@univ-lorraine.fr (Christel Métivier)
} 
than a century, with pioneering studies led by Bénard [1] and Rayleigh [2]. Several reviews have been proposed in [4]-[6]. The fluid layer is initially at rest, a vertical temperature gradient is imposed by heating the lower wall. The transition from conduction to convection is governed by the Rayleigh number $R a=\frac{\rho g \beta \Delta T d^{3}}{\mu \kappa}$, ratio between buoyancy effects and viscous and thermal diffusion effects, where $\rho$ is the fluid density, $g$ the gravitational acceleration, $\beta$ the thermal volume expansion, $\Delta T$ the temperature difference between walls, $\mu$ the fluid viscosity and $\kappa$ the thermal diffusivity. In the case of a Newtonian fluid with no-slip conditions at the walls, the critical Rayleigh number is $R a_{c}=1708$ with a supercritical bifurcation and the convection is characterized by rolls patterns [3].

These last decades, a growing interest has emerged for non-Newtonian fluids, certainly due to wide fields of applications (e.g. oil, cosmetic, pharmaceutic, food stuffs industries). In particular, we focus our study on shear-thinning fluids for which the viscosity $\mu$ decreases (non-linearly) with increasing shear rate $\dot{\gamma}$. First studies concerning the RBC in shear-thinning fluids were done by [7] and [8] who proposed, from experimental measurements, correlations between the Nusselt number $N u$ and the control parameters termed as the Rayleigh number $R a$, the Prandtl number $\operatorname{Pr}$ and rheological parameters for a relatively large range of $R a$ values $\left(10^{3}<R a<10^{6}\right)$. The rheological behaviour of the fluids used in their experiments were fitted by the power law model. This model presents a singularity as the shear rate $\dot{\gamma}$ tends to zero. Liang \& Acrivos [10] were the first to study experimentally the onset of convection in shear-thinning fluids, where the onset of convection is determined by using the Schmidt-Milverton principle [11]. The fluids used in [10] are aqueous solutions of polyacrylamide, characterized by a Newtonian plateau at low $\dot{\gamma}$ values. Due to this feature, the authors obtained a similar critical $R a$ number as in the Newtonian case. The main difference observed is that the heat transfer is larger in shear-thinning fluids than in Newtonian ones for increasing $R a$ values. This tendency has also been obtained in numerical study [12] where authors consider a power law model and Ellis model. More recently theoretical studies [13]-[15] have considered the $\mathrm{RBC}$ in Carreau fluids in an infinite extent cavity. In these articles, weakly non linear stability analyses have been used and have shown that the increase in $\alpha=$ $\left[\frac{d \mu^{*}}{d \Gamma^{*}}\right]_{\Gamma^{*}=0}$, the degree of shear-thinning, with $\Gamma^{*}=\dot{\gamma}_{i j}^{*} \dot{\gamma}_{i j}^{*}$ the second invariant of the shear rate tensor (here the star is used for dimensionless variables), leads to a transition from a supercritical bifurcation to a subcritical one. The critical value $\alpha_{c}$ is obtained equal to $24 /\left(601 \pi^{4}\right)$ for stress-free boundary conditions and $\alpha_{c} \approx 2.15 \times 10^{-4}$ for no-slip conditions, meaning that for $\alpha<\alpha_{c}$ the bifurcation is supercritical while above $\alpha_{c}$, the bifurcation is subcritical. Bouteraa et al. [15] have also studied the stability of the convective patterns near onset. They show that the only stable patterns are rolls in the supercritical bifurcation case. Finally, it is also shown that the degree of shear-thinning enhances the intensity of convection via the increase of heat transfer (Nusselt number $N u$ ) with the increase in $\alpha$. 
Since Liang \& Acrivos [10] in the 70's, there is no more experimental data. To our knowledge, flow visualizations concerning the RBC in shear-thinning fluids have never been performed. In this respect, we propose to study the onset of convection as well as patterns in shear-thinning fluids using nuclear Magnetic Resonance Imaging (MRI) in order to obtain flow visualizations and velocity maps. Very few studies on natural convection used MRI visualization technique [16], [17] while it gives velocity maps for opaque fluids or highly scattering media such as porous media [18], [19]. Concerning the RBC in shear-thinning fluids, as already indicated only few experimental results have been carried out in the past [7], [8], [10] but they have never proposed patterns vizualisations. We propose to study the Rayleigh-Bénard convection in aqueous solutions of Xanthan gum which present a Newtonian plateau at low values of $\dot{\gamma}$ and a shear-thinning behaviour above a critical value $\dot{\gamma}_{c}$. These fluids are well described by a Carreau model. In this sense, a first objective of our paper is to compare experimental results with theoretical ones given by [15], in terms of critical Rayleigh number, patterns stability and variations of heat transfer via the intensity of convection with rheological parameters. Another objective is to provide original results in the general topic of thermal convection in non-Newtonian fluids.

The section 2 of this paper details the fluids used in our experiments as well as their physical and rheological properties. The Rayleigh-Bénard setup is also presented and experimental protocols are explained. The section 3 focuses on experimental results near onset and above criticality. Results are discussed all along this section. The paper closes with a brief summary.

\section{Materials and methods}

Different fluids have been implemented in our work. First, we have chosen a Newtonian fluid (Glycerol) in order to validate our setup. The physical properties other than viscosity of Glycerol respectively thermal capacity $C_{p}$, thermal expansion coefficient $\beta$, density $\rho$ and conductivity $\Lambda$ in the temperature range $T=0-50^{\circ} \mathrm{C}$ are given by [22] based on data given by [21] :

$$
\begin{gathered}
C_{p g}(T)=4186.6 *(54+0.15 * T) * 10^{-2}\left[\mathrm{~J} /\left(\mathrm{kg} .{ }^{\circ} \mathrm{C}\right)\right] \\
\beta_{g}(T)=[47+0.2(T-20)] * 10^{-5}\left[1 /{ }^{\circ} \mathrm{C}\right] \\
\rho_{g}=1259\left[\mathrm{~kg} / \mathrm{m}^{3}\right] \\
\Lambda_{g}=0.28\left[\mathrm{~W} /\left(\mathrm{m} .{ }^{\circ} \mathrm{C}\right)\right]
\end{gathered}
$$

In Eqs. (1)-(4), the index $g$ is used to refer to Glycerol.

The shear-thinning fluids used in our experiments are aqueous solutions of Xanthan gum (Satiaxane CX 930, Cargill France). The Xanthan gum is a polysaccharide (five sugar residus) secreted by the bacterium Xanthomonas campestris. This polysaccharide is used in a wide range of applications such as cosmetic, oil, food industries but also in academic research [20]. The Xanthan gum is a polymer with a low ionic strength, soluble in water. Different concentrations of Xanthan gum in deionised water have been prepared : $0.1 \%, 0.15 \%$, 


\begin{tabular}{ccc}
\hline \hline Fluid & $C_{p}\left[\mathrm{~J} /\left(\mathrm{kg} .{ }^{\circ} \mathrm{C}\right)\right]$ & $\Lambda\left[\mathrm{W} /\left(\mathrm{m} .{ }^{\circ} \mathrm{C}\right)\right]$ \\
\hline Xanthan gum solution $(0.15 \%)$ & $0.895 T+4225.2$ & $0.0022 T+0.5153$ \\
\hline \hline
\end{tabular}

TABLE 1: Thermo-physical properties of Xanthan gum solution $(0.15 \%)$ as a function of the temperature $T\left({ }^{\circ} \mathrm{C}\right)$

$0.18 \%$ and $0.2 \%$. Solutions of Xanthan gum in water lead to transparent fluids and display a shear-thinning behaviour [20] which increases with the concentration as indicated in the following paragraph. Thermo-physical properties of the Xanthan gum solutions have been determined by means of a calorimeter ( $\mu$ dsc3-SETARAM). Because thermo-physical properties of the Xanthan gum solutions vary little in the range of concentrations aforementioned, we have only measured these properties for the concentration $0.15 \%$. Results obtained, in the range of temperature $\left[20^{\circ} \mathrm{C}, 60^{\circ} \mathrm{C}\right]$, for the heat capacity $C_{p}$ and for the thermal conductivity $\Lambda$ are given as function of the temperature $T\left({ }^{\circ} \mathrm{C}\right)$ in Table 1 .

\subsection{Rheological properties}

The rheological properties of the Glycerol and the Xanthan gum solutions have been measured by using a TA Instrument DHR3 rheometer with a coneplate geometry characterized by a $60 \mathrm{~mm}$ diameter and $1^{\circ}$ angle. Flow curves have been obtained for several temperature values in order to characterize the viscosity thermodependence.

The Glycerol is a Newtonian fluid, i.e. the viscosity remains constant for isothermal conditions. By varying temperature, the Glycerol viscosity varies as displayed in Fig. 1. The thermodependency of the Glycerol viscosity is modeled by the following exponential law :

$$
\mu(T)=\mu\left(T_{\text {ref }}\right) \exp \left(-K\left(T-T_{\text {ref }}\right)\right) .
$$

with $T_{\text {ref }}$ a reference temperature (here $T_{r e f}=24^{\circ} \mathrm{C}$ ) and $K$ the thermodependent coefficient. The dashed line in Fig. 1 corresponds to this model (Eq. (5)) with $K=0.0174^{\circ} \mathrm{C}^{-1}$ and $\mu\left(T_{r e f}\right)=0.31$ Pa.s.

The Xanthan gum solutions are shear-thinning fluids, i.e. the viscosity decreases with increasing shear rate $\dot{\gamma}$ (or shear stress $\tau$ ). Flow curves are displayed in Fig. 2 for the different Xanthan concentrations. The Xanthan solutions are fitted by a Carreau model defined by :

$$
\mu=\mu_{\infty}+\left(\mu_{0}-\mu_{\infty}\right)\left[1+(\lambda \dot{\gamma})^{2}\right]^{(n-1) / 2}
$$

where $\mu_{0}$ and $\mu_{\infty}$ set respectively for the viscosities at low and large shear rate, $n<1$ is the shear-thinning coefficient and $\lambda$ the characteristic time. Usually, $\mu_{\infty}$ is negligible [24] which is the case for the Xanthan solutions used in our study as one can observe in Fig. 2. Then, the Carreau model writes :

$$
\mu=\mu_{0}\left[1+(\lambda \dot{\gamma})^{2}\right]^{(n-1) / 2}
$$




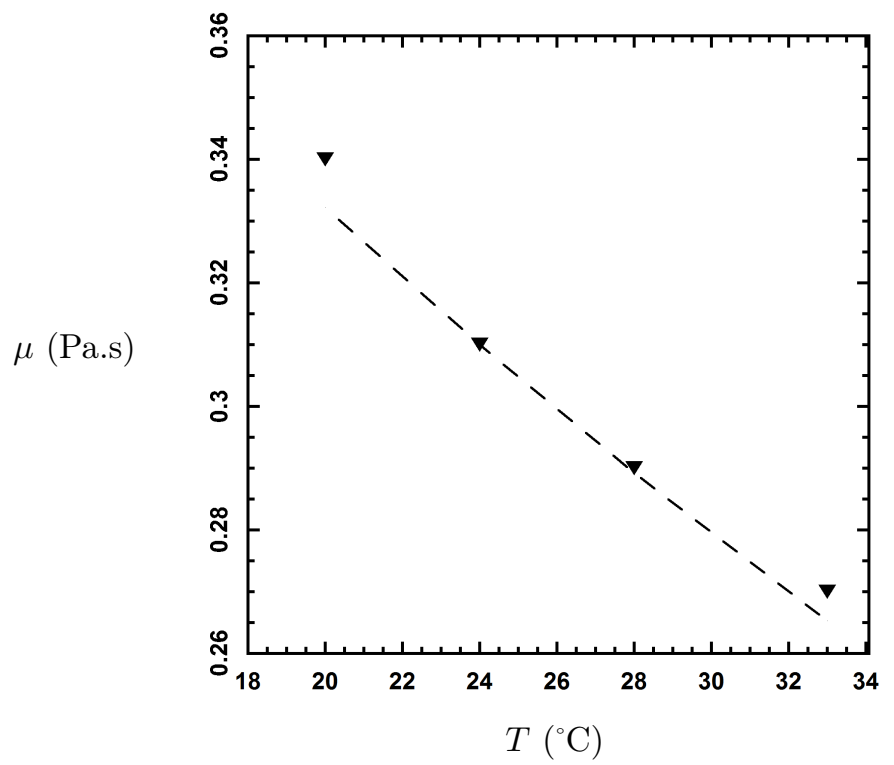

Figure 1: Variations of the Glycerol viscosity with temperature. The dashed line corresponds to the exponential model (5). With $K=0.0173^{\circ} \mathrm{C}^{-1}$ and $T_{r e f}=24^{\circ} \mathrm{C}$.

\begin{tabular}{ccccc}
\hline \hline $\mathrm{C} \%$ & $\mathrm{n}$ & $\lambda(\mathrm{s})$ & $\mu_{0}($ Pa.s $)$ & $\alpha$ \\
\hline 0.1 & 0.59 & 4 & 0.27 & $3.6910^{-7}$ \\
0.15 & 0.50 & 4.2 & 0.51 & $4.9610^{-7}$ \\
0.18 & 0.46 & 5.4 & 0.85 & $8.810^{-7}$ \\
0.2 & 0.44 & 11.4 & 1.77 & $4.310^{-6}$ \\
\hline \hline
\end{tabular}

TABle 2: Carreau rheological parameters of the Xanthan solutions for the different concentrations.

Values obtained for $\mu_{0}, n$ and $\lambda$ are summarized in Table 2 . These values are used in Fig. 2 in order to fit results (dashed lines). Furthermore, in order to compare our results with theoretical studies [13]-[15], the Table 2 displays the $\alpha=\frac{1-n}{2} \frac{\lambda^{2} \kappa^{2}}{d^{4}}$ values for each Xanthan gum concentrations. In the light of these values, one can expect a supercritical bifurcation and rolls pattern close to the onset of convection according to [15].

The thermodependency of the Xanthan solutions have also been investigated, flow curves are displayed in Fig. 3 for the $0.15 \%$ concentration. One observes that the viscosity variations with temperature are larger at low shear rate. Therefore, near the onset the thermodependency of viscosity is mainly governed by $\mu_{0}$. Similar tendencies are obtained for the other concentrations. The thermodependent viscosity is modeled by the exponential law given by Eq. (5) where 


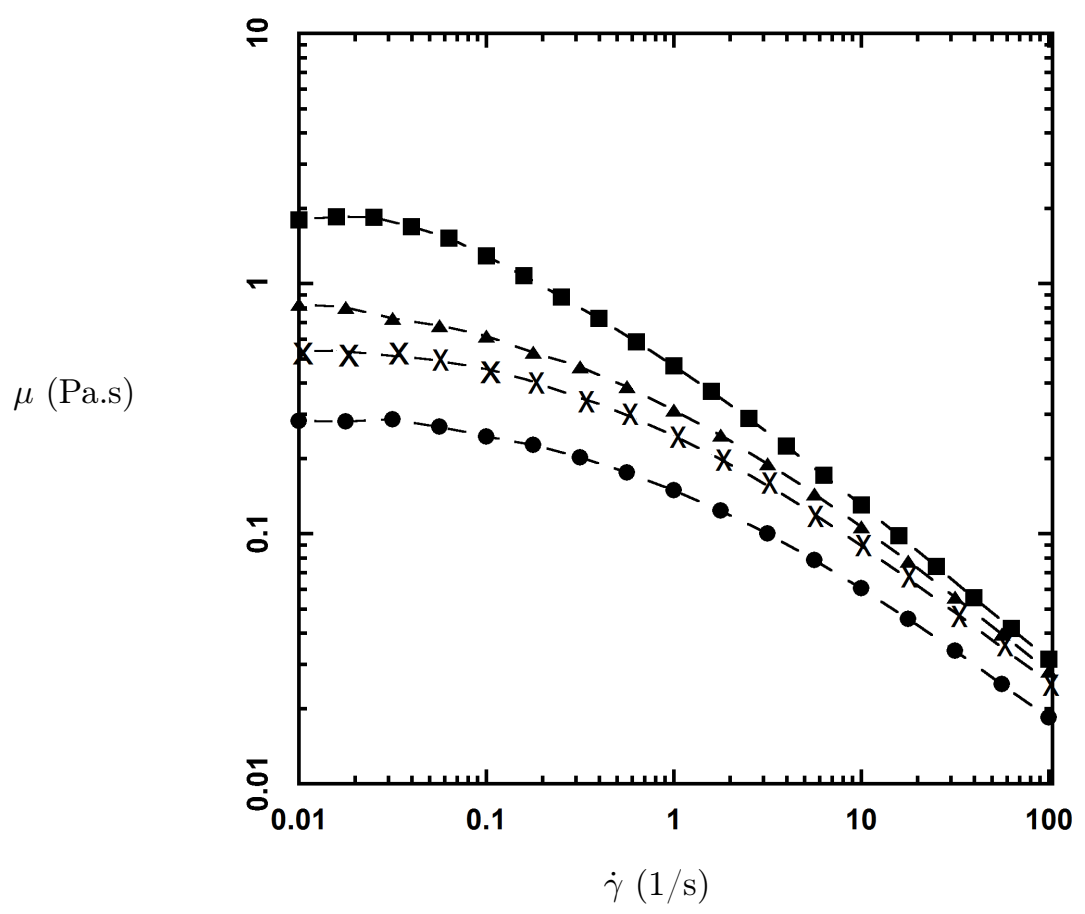

Figure 2: Flow curves of the Xanthan gum solutions at $T=24^{\circ} \mathrm{C}$. The dashed lines correspond to the Carreau model given by Eq. 7. $\bullet: 0.1 \%$ Xanthan gum concentration, $\times:$ Xanthan $0.15 \%, \boldsymbol{\Delta}$ : Xanthan $0.18 \%, \mathbf{\square}: 0.2 \%$ 


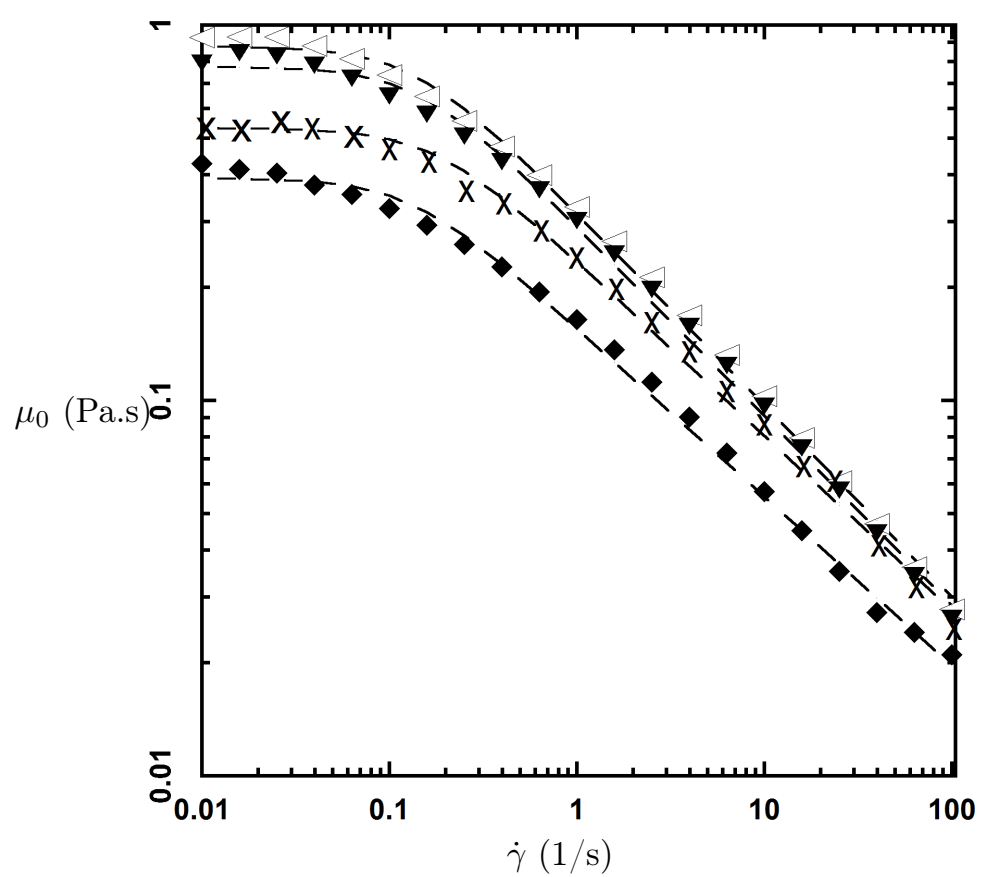

Figure 3: Flow curves of the $0.15 \%$ Xanthan solution at different temperatures. $\triangleleft: T=10^{\circ} \mathrm{C}$, $\boldsymbol{\nabla}: T=15^{\circ} \mathrm{C}, \times: T=24^{\circ} \mathrm{C}, \quad: T=30^{\circ} \mathrm{C}$. The dashed lines correspond to the Carreau model given by Eq. 7 .

$\mu$ is replaced by $\mu_{0}$ :

$$
\mu_{0}(T)=\mu_{0}\left(T_{r e f}\right) \exp \left(-K\left(T-T_{r e f}\right)\right)
$$

where $T_{\text {ref }}=24^{\circ} \mathrm{C}$ and $K=0.058{ }^{\circ} \mathrm{C}^{-1}, 0.048{ }^{\circ} \mathrm{C}^{-1}, 0.025{ }^{\circ} \mathrm{C}^{-1}$ and 0.023 ${ }^{\circ} \mathrm{C}^{-1}$ respectively for $0.1 \%, 0.15 \%, 0.18 \%$ and $0.2 \%$ Xanthan concentrations. The $K$ values aforementioned highlight a weak thermodependency of the Xanthan solutions, this would be discussed in the light of our results.

In the Rayleigh-Bénard situation, one usually defines the ratio $r$ between viscosities at upper and lower walls defined by :

$$
r=\frac{\mu\left(T_{c}\right)}{\mu\left(T_{H}\right)}=\frac{\mu_{\max }}{\mu_{\min }}
$$

which indicates the degree of viscosity variations with temperature in the fluid layer, $T_{c}$ (resp. $T_{H}$ ) being the cold (resp. hot) temperature at the upper (resp. lower) wall. For instance, in the case of the concentration $0.18 \%$, a temperature difference about $\Delta T=20^{\circ} \mathrm{C}$ leads to $r=1.65$, highlighting a weak viscosity dependence with temperature.

\subsection{Rayleigh-Bénard setup}

The fluid layer is confined in a cylindrical cell which is $D=120 \mathrm{~mm}$ in diameter and $d=20 \mathrm{~mm}$ thick providing an aspect ratio of $A=D / d=6$. 
The aspect ratio value is limited by the MRI resonator which corresponds to a cylinder (horizontal axe) of $160 \mathrm{~mm}$ diameter as explained in the following paragraph. Furthermore, the depth $d$ of the cavity has been chosen regarding the range of the fluids viscosity used. An objective of our study is to detect the onset of instability but also to investigate the convective motion above criticality. Because the maximal difference temperature has to be moderate in our experiments $\left(\Delta T<45^{\circ} \mathrm{C}\right)$, the value $d=20 \mathrm{~mm}$ was a good compromise.

All materials used in the setup have been chosen non-metallic to do not disturb the MRI measurements. The lateral walls are made of polymethyl methacrylate (PMMA) of $3 \mathrm{~mm}$ thick which is an insulated thermoplastic material. The horizontal walls are made of sapphire characterized by a thermal conductivity $\Lambda_{s}=35-40 \mathrm{~W} \cdot \mathrm{m}^{-1} \cdot \mathrm{K}^{-1}$ (at $20^{\circ} \mathrm{C}$ ). The horizontal walls temperatures are imposed by using circulating water obtained via refrigeration units. The water bath temperatures are set constant to within $\pm 0.01^{\circ} \mathrm{C}$. Water temperatures are measured with thermocouples at the inlets and outlets as described in the Fig. 4 which displays a cross-section in the $(O, x, z)$ plane of the setup, $O$ being the center of the fluid layer. One considers that the temperature of the upper and lower walls corresponds to the mean value between the respective water flow inlet and outlet. For relatively small values of $\Delta T$ (less than $20^{\circ} \mathrm{C}$ ), the respective differences between the inlet and outlet of the water flows are in the order of $0.1^{\circ} \mathrm{C}$. With the aim of maintaining a constant temperature difference between the upper and lower walls, the water flows are in opposite direction. The insulation of the whole system is obtained by adding $5 \mathrm{~mm}$ thick thermoplastic foam. Heat losses are also limited by fixing the mean temperature of the boundary layer to $T_{m}=24^{\circ} \mathrm{C}$ which corresponds to the temperature in the resonator.

One can evaluate the thermal diffusion time $\left(d^{2} / \kappa\right)$ in the Xanthan gum solutions around 1 hour. In this sense, the temperature difference across the layer was held for about 2 hours, in the conductive regime. Close to the conductiveconvective transition, the water bath temperatures were changed at equal rate in order to reach an additional difference temperature (step) of $0.5^{\circ} \mathrm{C}$. In this transition regime, each temperature step was maintained at least during 10 hours. When the temperature difference reaches about 3 times $\Delta T_{c}$, the minimal waiting time was 4 hours.

Finally, for all experiments, the upper and lower walls horizontality is reached within $0.035 \mathrm{rad}\left(\operatorname{around} 2^{\circ}\right)$.

\subsection{MRI technics and protocols}

Magnetic Resonance Imaging experiments were carried out on a Bruker Avance Biospec 24/40 spectrometer (2.34T, proton resonance frequency : 100.3 $\mathrm{MHz}$ ) equipped with a $200 \mathrm{~mm}$ inner diameter gradient coil and a $160 \mathrm{~mm}$ diameter quadrature resonator manufactured by Rapid Biomedical GmbH. Images are acquired using a flow encoding spin-echo protocol represented in Fig. 5, using the following parameters : repetition time (TR) : $1000 \mathrm{~ms}$, echo time (TE) : 28 $\mathrm{ms}$, field of view (FOV) : $12 \mathrm{~cm}$, matrix : $128^{*} 128$ pixels, spatial resolution 938 $* 938 \mu \mathrm{m}$. In order to encode velocity, gradient pulses of duration $\delta=4 \mathrm{~ms}$ with 


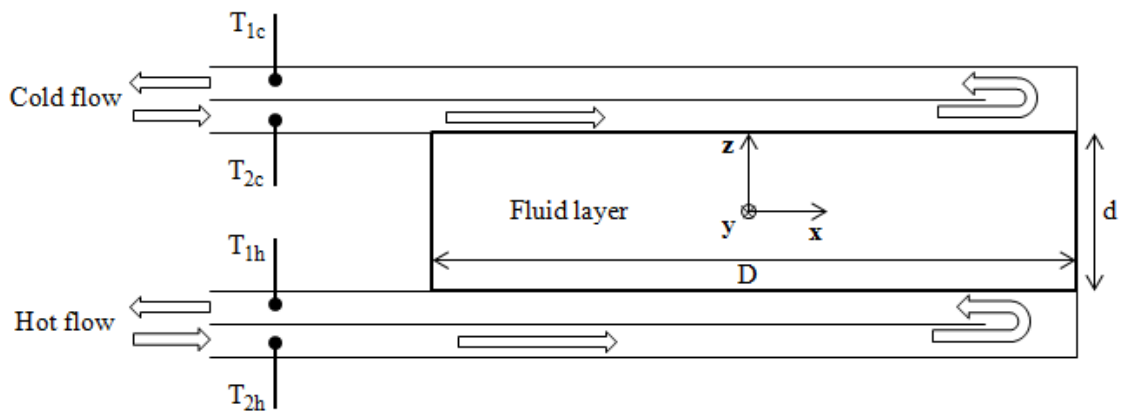

Figure 4: Rayleigh-Bénard setup

a separation of $\Delta=12 \mathrm{~ms}$ are used. In such images, the signal phase $\phi$ of a pixel is given by the relation :

$$
\phi=\gamma G \delta \Delta v
$$

with $\gamma$ the gyromagnetic ratio of the considered nucleus $\left(26.7510^{7} \mathrm{rad} . \mathrm{T}^{-1} \cdot \mathrm{s}^{-1}\right.$ for $\left.{ }^{1} \mathrm{H}\right), G$ the gradient pulses strength and $v$ the component of the velocity vector in the direction of the applied gradient.

The phase resolution of the spectrometer has been evaluated to $0.02 \mathrm{rad}$ according to previous works [23]. It leads to a velocity value close to $10^{-5} \mathrm{~m} / \mathrm{s}$. In this sense, we consider that the spectrometer resolution cannot allow us to detect the onset of motion when the velocity values are less than $5.10^{-5} \mathrm{~m} / \mathrm{s}$, i.e. 5 times the velocity resolution.

\subsection{Image analysis}

To obtain a velocity map, two experiments are performed with different gradient strengths of, respectively, $180 \mathrm{mT} / \mathrm{m}$ and $0 \mathrm{mT} / \mathrm{m}$. The phases of the two resulting images are then subtracted on a pixel by pixel basis in order to remove unwanted contributions. The setup dimensions described in section 2.2 have been defined and constrained by the spectrometer features, meaning the resonator size as well as the location of the maximal magnetic gradient intensity. Because the setup is quite large $(D=120 \mathrm{~mm})$, regions close to side walls lead to less accurate results or to gradient deviations. In order to remove these deviations, each velocity map have been subtracted to a reference map obtained in a fluid quiescent state at $T_{c}=T_{h}=T_{m}=24^{\circ} \mathrm{C}$.

Finally, images were passed through a filter in order to smooth spatial variations caused by the random noise. The smoothing algorithm, proposed by Garcia [26], is based on a penalized least square method and discrete cosine transform. 


\section{Experimental results and discussion}

\subsection{Newtonian fluid}

The setup has been validated by using a Newtonian fluid, i.e. the Glycerol characterized in the section above. Vertical velocity $V_{z}$ results are displayed in the horizontal $(O, x, y)$ plane for increasing $\Delta T$ (or $R a)$ values in Fig. 6. In this figure, the axes are indicated in pixels, we recall that 128 pixels correspond to $12 \mathrm{~cm}$. In Figure 6(a), velocity values are in the same order of magnitude as the MRI resolution, implying that one considers a conductive regime (no motion occurs). The transition from the conductive to the convective regime is observed in Fig. $6(\mathrm{~b})$, where $\Delta T=1.1^{\circ} \mathrm{C}$ leading to $R a=1784$. This value is in a very close agreement with the experimental results obtain in [27] and [28] who found $R a_{c} \approx 1800$ for $A=6$. By considering the onset of axisymmetric convection in a cylindrical cavity of finite extent, Charlson and Sani [29] have shown theoretically that the critical $R a$ value depends on $A$. The expression is explicitely given in [30] :

$$
R a_{c}(A)=\frac{\pi^{2} \zeta_{0}^{2}}{4 A^{2}} R a_{c}(\infty)+R a_{c}(\infty)
$$

with $\zeta_{0}^{2}=0.148$ for rigid-rigid boundary conditions after [31] and $R a_{c}(\infty)=$ 1708 is the critical Rayleigh number for $A=\infty$. In our case, $A=6$ leads to $R a_{c}(6)=1725$. This value can only gives an indication in the sense that non-axisymmetric solutions are observed for low $A$ values after [25].

Concerning the patterns, we find some parallel rolls close to the onset as displayed in Fig. 6. The wave number $k=2 \pi d / \lambda$, with $\lambda$ the wave length, is evaluated to $3.2 \pm 0.1$. These results agree with the experimental results of [27] and [28]. Above criticality it is worth noting that rolls are deformed leading to a "Y" pattern as one can see in Figs. 6(c) and 6(d)).

Maximal values of velocity $V_{z \max }$ are displayed as a function of $R a$ in Fig. 7. An axis corresponding to the dimensionless velocity $V_{z}^{*}$, defined by the ratio between $V_{z}$ and the buoyancy velocity $\sqrt{g \beta \Delta T_{c} d}$, has also been added. In this Figure, a theoretical result (continuous line), obtained with a weakly non-linear stability analysis at the 7th order calculations for the perturbation mode (see [15] for the detailed method), has been plotted. One can observe that the velocity $V_{z \max }$ increases with the increase of the Rayleigh number, i.e the temperature differences $\Delta T$, in agreement with the theoretical variations. Differences with theory are larger for low values of $R a$ where experimental values are close to the measurements accuracy.

\subsection{Non-Newtonian fluid - Xanthan gum}

\subsubsection{Onset of convection}

We now focus on the experimental Rayleigh-Bénard convection in a shearthinning fluid, the Xanthan gum solutions. Results for the different concentrations used are displayed in Fig. 8 in terms of vertical velocity map in the 
horizontal mid-plane $(O, x, y)$ of the cavity. The onset of convection is observed for all these concentrations around the Rayleigh value $R a_{c}=1800 \pm 4 \%$ which corresponds to the Newtonian value within our experiments accuracy. These results confirm a supercritical bifurcation which agrees with the theoretical prediction regarding the range of $\alpha$ values as already discussed. However, one can notice that maximal velocity values below criticality is about 3 times the measurements resolution. While the maximal velocity values remain weak below $R a_{c}=1800$, one could think that one cell convective pattern have appeared for $R a<1800$ by considering the Fig. 8. A convective motion could occur below criticality due to either a defect in the cavity horizontality or a horizontal temperature gradient in the upper and lower walls. Yet, as already discussed in paragraph 2.2, these defects remain very weak. It does not seem to perturb the critical $R a$ value since one finds $R a_{c} \approx 1800$ for each fluid (Newtonian and non-Newtonian).

Concerning the patterns, one observes that close to the onset of convection, straight rolls characterized by a wave number of $3 \pm 0.1$ appear for the lowest concentration used in this study, i.e. $0.1 \%$ of Xanthan gum (see Fig. 8(b)). When the Xanthan concentration is slightly increased, one observes convective cells (polygons) at the onset of convection. In the case of the concentration 0.15 $\%$, (imperfect) straigth rolls are observed just above the criticality. However, the polygons remain stable above criticality for $0.18 \%$ and $0.2 \%$ Xanthan gum concentrations as shown in Figs. $8(\mathrm{~g})$ and $8(\mathrm{i})$ for $R a \approx 2100$. Our results disagree with those predicted by theory [15], since in the range of our $\alpha$ values, only rolls are found stable at the onset of convection. The increase in concentration in our experiments increases the viscosity plateau $\mu_{0}$, hence increases also the critical $\Delta T$ value needed to start the convection. In [15], the degree of viscosity variations $r$ defined in Eq. (9) is fixed at 1 . In our experiments, we can evaluate this parameter at criticality, $r\left(R a_{c}\right)$, we find values around 1.3-1.4 for the largest concentrations and 1.25 for a concentration of $0.1 \%$. In this range of $r$ values, it does not seem that the viscosity thermodependency could involve convective cells as polygons, squares for instance according to [22], [32]-[34]. In these articles, it is shown that the rolls are stable for low values of $r$, i.e. for $r \leq r_{1}$ with $r_{1} \approx 2$ in [33] and $r_{1} \approx 3$ in [34]. Above $r_{1}$ squares are stable and the convection remains supercritical. At low $R a$ values, hexagons could also be the stable patterns for larger viscosity variations [35], [36], yet it does not correspond to our experimental conditions.

Different parameters could cause the existence of polygons at the onset of convection, such as a large Prandtl values $\left(O\left(10^{3}\right)\right)$ combined with thermodependency and imperfect boundary conditions i.e. finite conductivity at walls [34], [32], imperfect insulated lateral walls. We have checked each parameter. The use of sapphire as horizontal walls lead to a conductivity ratio between the wall and the fluid equal to $\xi=\frac{\Lambda_{w}}{\Lambda_{f}} \approx 100$. Regarding results given by [32]-[34], one finds that in our range of Prandtl values $\left(\operatorname{Pr}=O\left(10^{3}\right)\right)$, the stable patterns are rolls. The influence of the lateral walls can be evaluated via the wall admittance defined by $C=\left(D / 2 \Lambda_{f}\right) /\left(t_{l w} / \Lambda_{l w}\right)$, where $t_{l w}$ stands for the lateral wall 
thickness and $\Lambda_{l w}$ is the lateral wall conductivity. Our experimental setup leads to $C \approx 80$ which is quite large (insulated lateral wall).

Finally, the polygons pattern remains stable for larger values of $R a$ when the Xanthan gum concentration increases. It also leads to an increase in $\Delta T_{c}$ values. Concerning this point, $\Delta T_{c}$ values can reach the order of $10^{\circ} \mathrm{C}$, in the case of the 0.18 and $0.2 \%$ concentrations, corresponding to large values and inducing variations in values of thermo-physical parameters within $10 \%$ around that ones obtained at the horizontal walls temperature average. Thus, the comparison with theoretical results which use the Boussinesq approximation is no longer valid. Indeed, a theoretical study [37] has shown that when all physical properties (e.g. density, conductivity, thermal heat capacity) depend with temperature, i.e. a non Oberbeck-Boussinesq (non-OB) convection case, a bistability of hexagonal and roll patterns occurs. In this study, the author has shown that when the thermodependency of properties is large enough to involve asymmetric conditions in the fluid layer, the convection starts via a subcritical bifurcation to hexagons from $R a \geq R a_{A}$. Busse [37] has shown that hexagons are the prefered patterns for $R a_{A}<R a<R a_{R}$. By increasing the $R a$ values, a region of bistability is observed for $R a_{R}<R a<R a_{B}$, meaning that both hexagons and rolls are stable. Finally, rolls are the prefered patterns for $R a>R a_{B}$ (see Fig. 2 in [37]). These results have also been observed experimentally in [30], [38]-[42]. It is the a

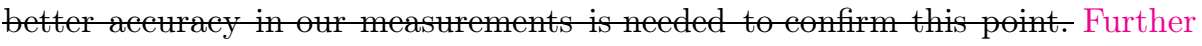
experimental investigations led by [43] confirm that the polygons we have observed are hexagons. Similarly to Dubois et al. [40], we observe that the critical Rayleigh number is nearly similar to the one obtained in the Boussinesq case. In the range of our experiments accuracy, we do not observe any jump in the maximal vertical velocity (see Fig. 13) neither any hysteresis at the first threshold similarly to [40] but unlike in [41]. In this sense, if the hexagons bifurcation is subcritical as predicted by [37] for hexagons, then it is weak and not observable in the range of our experimental conditions.

\subsubsection{Above criticality}

In this paragraph, we present results when $R a$ values are increased above criticality. The patterns evolution is displayed for each Xanthan gum concentration in Figs. 9-12. Maximal velocity values $V_{z \max }$ and $V_{z \max }^{*}$, obtained in the mid-plane $(O, x, y)$, are displayed as a function of $R a$ values in Fig. 13 for the different Xanthan gum concentrations except for $0.2 \%$ where technical problems reduced the accuracy of these measurements.

As previously, some differences in terms of pattern are observed by varying the Xanthan gum concentration. For low values of concentrations, i.e. $0.1 \%$ and $0.15 \%$, it is found that rolls remain stable until $R a \approx 5600$ for $0.15 \%$, even if one could notice some changes in the thermoconvective structures before this latter value. For instance, we could underline slight modidifications around $R a=3500$ (see Figs. 10(b) and 10(c) for the concentration $0.15 \%$ ) and also around $R a=5600-5800$ (see Figs. $10(\mathrm{~g})$ and $10(\mathrm{~h})$ for the concentration 0.15 
\%). These modifications in terms of structure can also be observed in Fig. 13 where there exists a discrepancy in $V_{z \max }$ values around $R a \approx 3500$ in the case $0.15 \%$ (cross symbols) which corresponds to a change in the rolls patterns.

When the concentration is increased, one notices that hexagons could remain stable further above criticality until $R a \approx 2800$ for the concentration $0.18 \%$ and $R a \geq 2900$ for the concentration $0.2 \%$. in Fig. 11(a), 11(b), 11(e), 12(e) $12(\mathrm{f})$, in plat

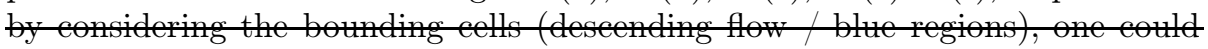

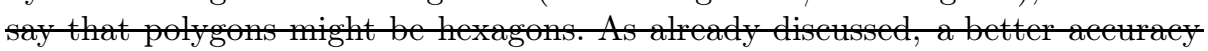

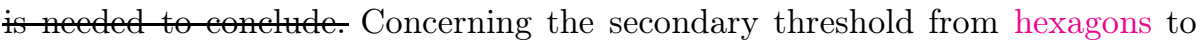
rolls, in the $0.18 \%$ case, one observes that the change in pattern also involves a discrepancy in terms of velocity values $V_{z \max }$ as diplayed in Fig. 13 (open triangles in the case of $0.18 \%$ ). Actually, one can observe a first discrepancy in $V_{z \max }$ values around $R a \approx 2300$. This first discrepancy is not correlated with a change in the structure but only with the increase in convective motion, see for comparison Figs. 8(g) and 11(a). The second discrepancy occurs around $R a \approx 2800$ where the pattern changes from hexagons to rolls. One notices that for $2500 \lesssim R a \lesssim 2800$, the maximal velocity value in the mid-plane does not vary significantly $\left(V_{z \max } \approx 8.610^{-5} \mathrm{~m} / \mathrm{s}\right)$, the large increase in $V_{z \max }$ occurs at $R a=2925$ for which $V_{z \max } \approx 1.210^{-4} \mathrm{~m} / \mathrm{s}$. Then at $R a=3028$, the maximal velocity value decreases to $V_{z \max } \approx 810^{-5} \mathrm{~m} / \mathrm{s}$. The remarkable discrepancy in velocity values has also been observed in [40]. It is associated to the jump from the hexagonal patterns solution to the rolls solution in the range $R a_{R}<R a<R a_{B}$. In our case, it means that for the Xanthan gum concentration of $0.18 \%$, we obtain $R a_{B} \approx 3000$. Increasing then decreasing $R a$ involves a hysteresis loop between hexagons and rolls in this latter $R a$ range values as predicted by [37] for hexagons and experimentally observed by e.g. [30], [40], [41]. In our experiments, this hysteresis is not such clear. When $R a$ is decreased, one can observe in Fig. 14 that rolls remain stable for smaller values of $R a$ compared with Fig. 11. However, it is possible that rolls and hexagons co-exist in the range $2300<R a<2800$. This observation is confirmed by considering Fig. 15 where $V_{z \max }$ is displayed for increasing and decreasing $R a$. The straight line corresponds to the weakly non linear solution for rolls. One can observe that experimental results are close when increasing and decreasing $R a$ and larger than expected results in the case of rolls only (theoretical curve). Finally when $R a<2300$, only hexagons exist, meaning that $R a_{R} \approx 2300$. However, further resolution is required in order to determine more accurately this hysteresis loop if it exists effectively in non-Newtonian fluids.

Concerning the patterns, at $R a \approx 2300$, one can highlight an azimutal wave number $m$ equal to 4 . For hexagons, the wave number obtained for Xanthan concentrations of $0.18 \%$ and $0.2 \%$ (Figs. $11(\mathrm{a})$ and $12(\mathrm{a})$ ) can be evaluated to $k_{h}=4 \pi d / \sqrt{3} \lambda_{h}=3.5 \pm 0.1$, where $\lambda_{h}$ corresponds to the separation of adjacent rising regions. This value is larger than 3.07 or 3.2 obtained for hexagons, respectively in [42] and [40] in the Newtonian case. One can notice that the increase in $R a$ increases the azimutal wave number since for $R a \approx 2800, m=7$ (see Fig. 12(e)). The increase in $m$ finally leads to a transition from hexagons 
to rolls pattern.

Finally, considering the maximal velocity variations with $R a$ when the concentrations vary, one notices that (i) the order of $V_{z \max }$ values are larger than in the Newtonian case highlighting a more intense convection in the non-Newtonian case as shown in experimental [10] and theoretical [13]-[15] studies and (ii) the order of $V_{z \max }$ values are the same in the range of tested Xanthan concentrations. In this sense, it seems that the intensity of convection is quite similar in this range of concentration as predicted by the theory [15]. It was not possible to evaluate more accuratly the intensity of convection, in particular through heat flux measurements, since only non-metallic materials could be used in the MRI resonator.

\subsubsection{Shear rate $\dot{\gamma}$ evaluation}

Because the range of velocity values obtained is similar for all tested concentrations, we only focus on one concentration case, say $0.15 \%$, in order to evaluate the main shear rate tensor component. Due to the orientation of the rolls, the main component in the mid-plane $(O, x, y)$ is the $\dot{\gamma}_{x z}$ one which is represented in Fig. 16 for three values of $R a$. The structure of $\dot{\gamma}_{x z}$ values is obviously correlated with the pattern observed via the velocity maps. More important is the increase of the $\dot{\gamma}_{x z}$ values from $O\left(10^{-3}\right) \mathrm{s}^{-1}$ to $O\left(10^{-2}\right) \mathrm{s}^{-1}$ by increasing $R a$ from 2000 to 6000 respectively. It has been shown by Cocci et al [44], Picot et al [45], Loulou et al [46], that the thermal conductivity can be a function of shear rate. Nevertheless, for the range of $\dot{\gamma}$ values involved in our experiments, the modification of the thermal conductivity is weak (few percents) and could be neglected. One could have expected larger increase in shear-rate in this range of $R a$ values. However, one knows that larger shear-rate values are obtained close to walls. Figures 17 and 18 display respectively velocity components $\left(V_{x}\right.$ and $\left.V_{z}\right)$ in the vertical plane $(O, x, z)$ and the main shear rate component $\dot{\gamma}_{x z}$ in the same plane. Since $\dot{\gamma}_{x z} \gg \dot{\gamma}_{z z}$, the second invariant of the shear rate tensor is such as $|\dot{\gamma}| \sim\left|\dot{\gamma}_{x z}\right|$. It is worth noting that the shear rate has not been evaluated close to walls due to a lack of accuracy in these regions. Considering Fig. 18 one founds similar $\dot{\gamma}_{x z}$ values to that of obtained in the mid-plane. This is not surprising because we expect larger values close to walls. The shear-rate evaluation at walls $\left|\dot{\gamma}_{w}\right|$ can be approximated by :

$$
\left|\dot{\gamma}_{w}\right| \sim \frac{\Delta V_{z}}{\Delta x}
$$

where $\Delta x$ corresponds to the thickness where the measurements are inaccurate in the fluid close to walls. Typically, one obtains few pixels corresponding to $\Delta x=0.1 \mathrm{~mm}$. By considering no-slip conditions at walls, one finally obtains $\left|\dot{\gamma}_{w}\right|=O\left(10^{-2}\right) s^{-1}$ close to criticality and $\left|\dot{\gamma}_{w}\right|=O\left(10^{-1}\right) s^{-1}$ for $R a \gtrsim 2 R a_{c}$. These values correspond to maximal $|\dot{\gamma}|$ values in the flow. One can notice that close to criticality, the $\left|\dot{\gamma}_{w}\right|$ value corresponds to the Newtonian plateau as displayed in Fig. 2. This is not surprising since we have not observed any subcritical bifurcation for this concentration which means that the increase in velocity and $|\dot{\gamma}|$ values is continuous starting from a fluid at rest. When the $R a$ 
value is increased, around $R a \gtrsim 2 R a_{c}$, one notices that the $|\dot{\gamma}|$ values are such as the viscosity is no longer constant in the whole cavity since the fluid behaves as a shear-thinning fluid for $|\dot{\gamma}| \geq 0.1 \mathrm{~s}^{-1}$. In this sense, close to criticality our results can be compared with that of the Newtonian fluids case (in the range of our tested fluids), while main differences should occur above criticality.

\section{Conclusion}

An experimental investigation of the Rayleigh-Bénard convection in shearthinning fluids is presented by using MRI technics. Flow visualizations are presented via velocity mapping for a Newtonian fluid, the Glycerol and for shearthinning fluids, Xanthan gum aqueous solutions with weight concentrations ranging from 0.1 to $0.2 \%$.

In the case of the Glycerol and Xanthan solution at $0.1 \%$, one recovers similar results in terms of criticality with $R a_{c}=1800$ and patterns since the convection is characterized by rolls. When the Xanthan concentration is increased, the critical Rayleigh number is not modified, however the onset occurs with hexagonal pattern. Buse these patterns are due to non Oberbeck-Boussinesq effects. Similarities with results obtained in the Newtonian case are highlighted. We have observed a transition from hexagonal patterns to rolls as predicted by [37] and observed by [40], [42]. However, the subcritical transition from conduction to convection with hexagons as well as the hysteresis loop are not clearly observed in our study. In this sense, further theoretical and experimental investigations are needed to study the RBC in shear-thinning fluids when physical properties vary strongly with temperature.

Concerning the experimental technique, an ongoing work consits on obtaining both temperature and velocity mapping by using the MRI. The knowlegdege of temperature as well as temperature gradients and velocity are essential in natural convection studies. Furthermore, in future works the use of MRI could allow us to consider a large variety of industrial or natural fluids which are usually fluids where other velocity imaging methods are not usable since they could be opaque for instance.

\section{Acknowledgments}

The work of the authors has been supported by the French National Agency of Research (ANR), grant called "ThiM" and by the Fédération Jacques Villermaux.

\section{Références}

[1] Bénard H., Etude expérimentale du mouvement des liquides propageant de la chaleur par convection. Régime permanent : tourbillons cellulaires. Compterendus de l'Académie des Sciences, 130, 1004-1007 (1900). 
[2] Rayleigh L., On convective currents in a horizontal layer of fluid when the higher temperature is on the under side, Phil. Mag., 32, 529-546 (1916).

[3] Schluter A., Lortz D. \& Busse F. On the stability of steady finite amplitude convection J. Fluid Mech. 23, 129 (1965)

[4] Getling A.V.., Rayleigh-Bénard convection : structures and dynamics, Vol. 11, World Scientific (1998).

[5] Koschmieder E. L., Bénard Cells and Taylor Vortices, Cambridge University Press (1993).

[6] Bodenschatz E., Pesch W. and Ahlers G., Recent developments in RayleighBénard convection, Annu. Rev. Fluid Mech. (2000).

[7] Pierre ST. C. and Tien C., Experimental investigation of natural convection heat transfer in confined space for non-Newtonian fluid, Can. J. Chem. Engng , 41, 122-127 (1963).

[8] Tsuei H. and Tien C., Free convection heat transfer in a horizontal layer of non Newtonian fluid, Can. J. Chem. Engng 51, 249-251 (1973).

[9] Tien C., Tsuei H. and Sun Z., Thermal instability of a horizontal layer of non Newtonian fluid heated from below, Intl J. Heat Mass Transfer 12, 1173-1178 (1969).

[10] S. F. Liang, and A. Acrivos Experiments on buoyancy-driven convection in non-Newtonian fluids, Rheol. Acta 9, 447-455 (1970).

[11] Schmidt R.J., and Milverton S.W. On the instability of a fluid when heated from below, Proc. R. Soc. London, Ser. A 152, 586-594 (1935).

[12] H. Ozoe, and W. Churchill. Hydrodynamic stability and natural convection in Ostwald de-Waele and Ellis fluids : the development of a numerical solution, AIChE J. 18 (6), 1196-1207 (1972).

[13] N. J. Balmforth, A. Rust, Weakly nonlinear viscoplastic convection, J. Non-Newtonian Fluid Mech. 158, 36 (2009).

[14] B. Albaalbaki, R. E. Khayat, Pattern selection in the thermal convection of non-Newtonian fluids, J. Fluid Mech. 668, 500 (2011).

[15] Bouteraa M., Nouar C., Plaut E., Métivier C., and Kalck A., Weakly nonlinear analysis of Rayleigh-Bénard convection in shear-thinning fluids : nature of the bifurcation and pattern selection, J. Fluid Mech. 767, 696-734 (2015).

[16] Gibbs S.J., Carpentier T.A., and Hall L.D., Magnetic resonance imaging of thermal convection, J. Magn. Reson., Ser. A 105, 209-214 (1993). 
[17] Weis J., Kimmich R., and Muller H.P., NMR imaging of thermal convection patterns, Magn. Reson. Imaging, 14 (3), 319-327 (1996).

[18] Shattuck M.D., Behringer R.P., Johnson G.A. and Georgiadis J.G., Convection and flow in porous media. Part 1 . Visualization by magnetic resonance imaging, J. Fluid Mech. 332, 215-245 (1997).

[19] Weber M. and Kimmich R., Rayleigh-Bénard percolation transition of thermal convection in porous media : Computational fluid dynamics, NMR velocity mappin, NMR temperature mapping, Phys. Rev. E, 056301 (2002).

[20] Song K.W., Kim Y.S. and Chang G.S., Rheology of concentrated xanthan gum solutions : Steady shear flow behavior. Fibers and Polymers, 7(2), 129138 (2006).

[21] A. A. Newman . Glycerol, CRC Press (1968)

[22] Stengel K.C., Oliver D.S., Booker J.R. Onset of convection in a variableviscosity fluid, J. Fluid Mech. 120, 411-431 (1982)

[23] Salameh W. Imagerie par résonance magnétique nucléaire pour la vélocimétrie d'un écoulement en milieu poreux. Ph.D. thesis, Institut National Polytechnique de Lorraine, 2011.

[24] Bird R.B., Amstrong R. \& Hassager O. Dynamics of polymeric liquids, New York : Wiley-Interscience (1987)

[25] Buell J.C. \& Catton I. The effect of wall conduction on the stability of a fluid in a right circular cylinder heated from below, ASME J. Heat Transfer 105, $225(1983)$

[26] Garcia D. Robust smoothing of gridded data in one and higher dimensions with missing values, Computational Statistics and Data Analysis 54, 1167 (2010)

[27] Hébert F., Hufschmid R., Scheel J. \& Ahlers G. Onset of Rayleigh-Bénard convection in cylindrical containers, Phys. Rev. E 81, 046318 (2010)

[28] Stork K., Muller U. Convection in boxes : an experimental investigation in vertical cylinders and annuli, J. Fluid Mech. 71, part 2 231-240 (1975)

[29] Charlson G.S. \& Sani R.L. Thermoconvective instability in a bounded cylindrical fluid layer, Int. J. Heat Mass Transfer 13, 1479 (1970)

[30] Pampaloni E., Perez-Garcia C., Albavetti L. \& Ciliberto S. Transition form hexagons to rolls in convection in fluids under non-Boussinesq conditions, J. Fluid Mech. 234, 393-416 (1992)

[31] Wesfreid J., Pomeau Y., Dubois M., Normand C. \& Bergé P. Critical effects in Rayleigh-Bénard convection, J. Phys. Lett. 39, 725 (1978) 
[32] Jenkins D.R., \& Proctor M.R.E. The transition from roll to square-cell solutions in Rayleigh-Bénard convection, J. Fluid Mech. 139, 461-471 (1984)

[33] Busse F.H., Frick H. Square-pattern convection in fluids with strongly temperature-dependent viscosity, J. Fluid Mech. 150, 451-465 (1985)

[34] Jenkins D.R. Rolls versus squares in thermal convection of fluids with temperature-dependent viscosity, J. Fluid Mech. 178, 491-506 (1987)

[35] Richter F.M. Experiments on the stability of convection rolls in fluids whose viscosity depends on temperature, J. Fluid Mech. 89, 553-560 (1978)

[36] White D.B. Planforms and onset of convection with temperature-dependent viscosity, J. Fluid Mech. 191, 247-286 (1988)

[37] Busse F.H. The stability of finite amplitude cellular convection and its relation to an extremum principle, J. Fluid Mech. 30 part 4, 625-649 (1967)

[38] Hoard C.Q., Robertson C.R. \& Acrivos A. Experiments on the cellular structure in Bénard convection, Int. J. Heat Mass Transfer 13, 849-856 (1970)

[39] Somerscales E.F.C. \& Dougherty T.S. Observed flow patterns at the initiation of convection in a horizontal liquid layer heated from below, J. Fluid Mech. 42 part 4 755-768 (1970)

[40] Dubois M., Bergé P. \& Wesfreid J. Non-Boussinesq convective structures in water near $4^{\circ} \mathrm{C}$, J. Phys. 39, 1253-1257 (1978)

[41] Walden R. W. \& Ahlers G. Non-Boussinesq and penetrative convection in cylindrical cell, J. Fluid Mech. 109 89-114 (1981)

[42] Bodenschatz E., de Bruyn J.R., Ahlers G. \& Cannell D.S. Transitions between patterns in thermal convection, Phys. Rev. Lett. 67 (22) 3078-3081 (1991)

[43] Bouteraa M. Titre thèse??. PhD thesis, Université de Lorraine, to be published 2016.

[44] Cocci A.A. \& Picot J.J.C. Rate of strain effect on thermal conductivity of polymer liquid, Polymer Engng Sci. 13 337- (1973)

[45] Picot J.J.C., Goobie G.I. \& Mawhinney G.S. Shear induced anisotropy in thermal conductivity of polyethylene melt, Polymer Engng Sci. 22 154- (1982)

[46] Loulou T., Peerhossaini H. \& Bardon J.P. Etude expérimentale de la conductivité thermique de fluides non-Newtoniens sous cisaillement application aux solutions de Carbopol 940, Int. J. Heat Mass Transfer 3510 2557$2562(1992)$ 


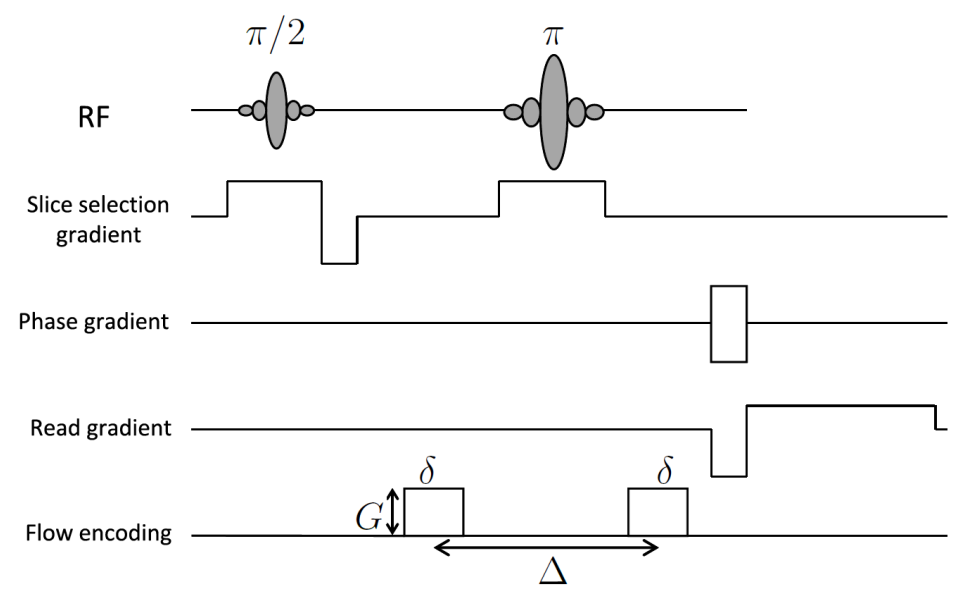

Figure 5: Magnetic resonance imaging (MRI) pulse sequence used for acquiring velocity map. The flow encoding direction may be any of the three gradient directions (read, phase or slice).
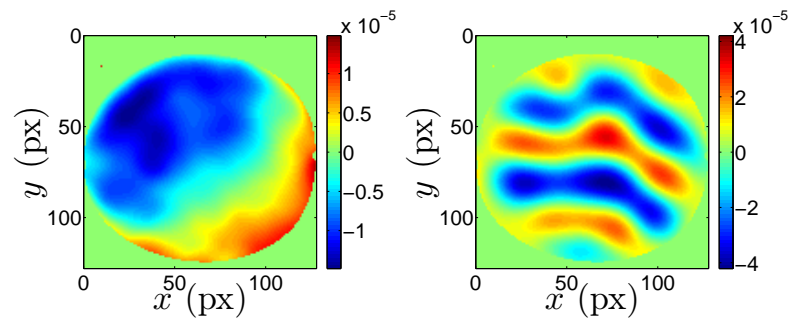

(a) $\Delta T=0.5^{\circ} \mathrm{C}, R a=811$

(b) $\Delta T=1.1^{\circ} \mathrm{C}, R a=1784$
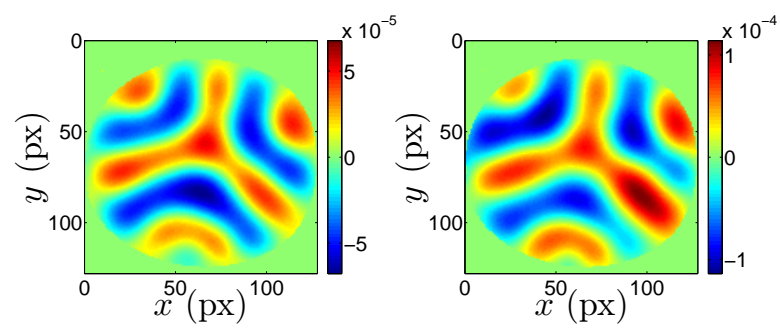

(c) $\Delta T=1.6^{\circ} \mathrm{C}, R a=2594$

(d) $\Delta T=3.5^{\circ} \mathrm{C}, R a=5675$

Figure 6: Vertical velocity $V_{z}(\mathrm{~m} / \mathrm{s})$ in the $(O, x, y)$ plane with increasing $R a$ values for the Glycerol case 


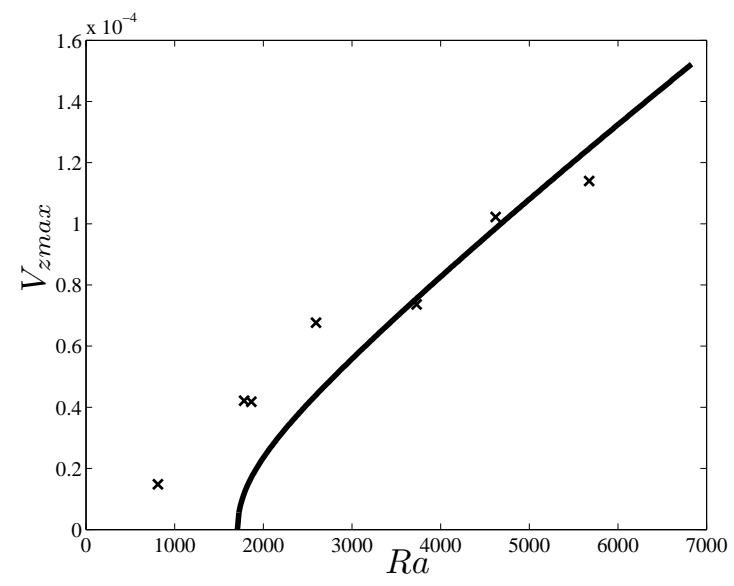

(a) $V_{z \max }(\mathrm{m} / \mathrm{s})$

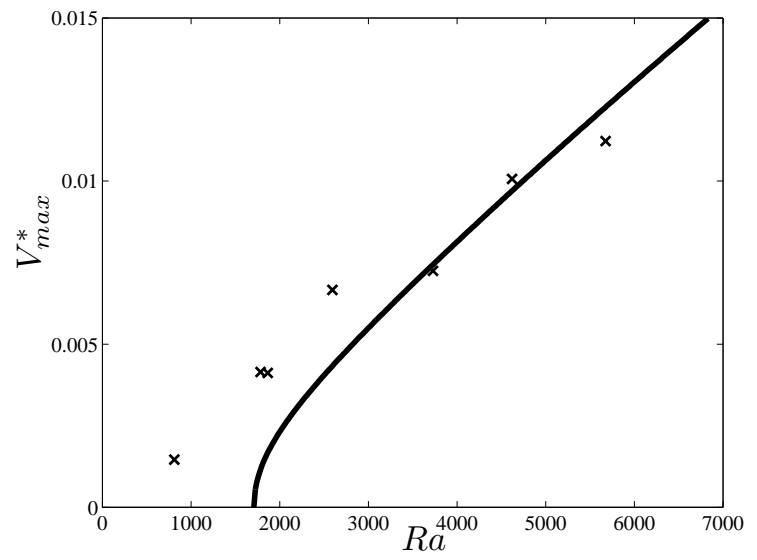

(b) Dimensionless maximal velocity $V_{\max }^{*}$

Figure 7: Maximal velocity values (a) $V_{z \max }(\mathrm{m} / \mathrm{s})$, (b) $V_{\max }^{*}$ as a function of the Rayleigh number for the Glycerol - Continuous line corresponds to the theoretical result 


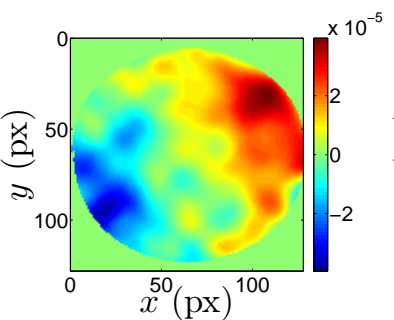

(a) $\Delta T=2.7^{\circ} \mathrm{C}, R a=1240$

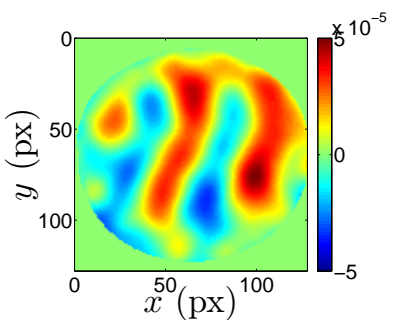

(b) $\Delta T=3.8^{\circ} \mathrm{C}, R a=1750$

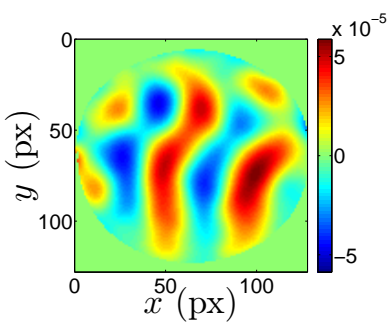

(c) $\Delta T=4.4^{\circ} \mathrm{C}, R a=$ 2026.2

$0.1 \%$ of Xanthan gum solution

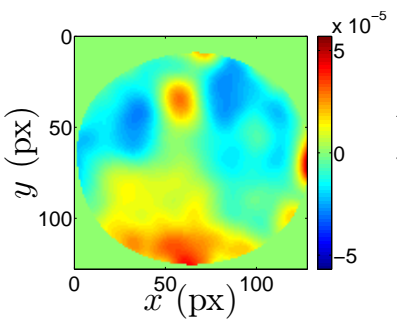

(d) $\Delta T=6.7^{\circ} \mathrm{C}, R a=1829$

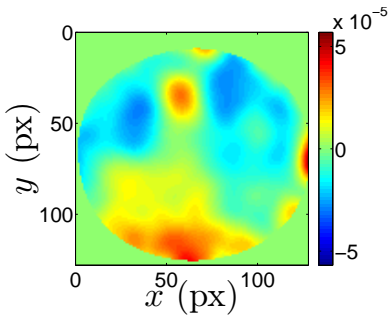

(e) $\Delta T=6.7^{\circ} \mathrm{C}, R a=1829$

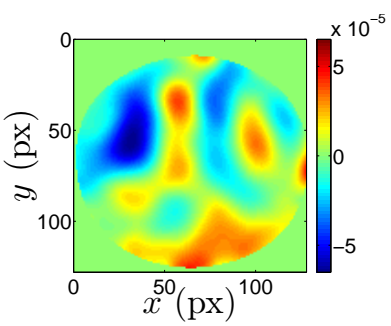

(f) $\Delta T=7.7^{\circ} \mathrm{C}, \mathrm{Ra}=2102$

$0.15 \%$ of Xanthan gum solution

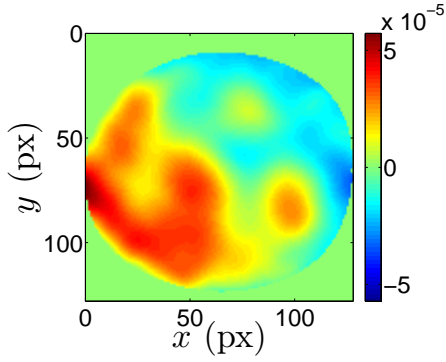

(g) $\Delta T=10.85^{\circ} \mathrm{C}, R a=1867$

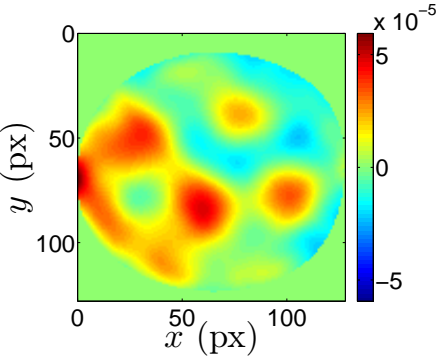

(h) $\Delta T=12.6^{\circ} \mathrm{C}, R a=2168$

$0.18 \%$ of Xanthan gum solution

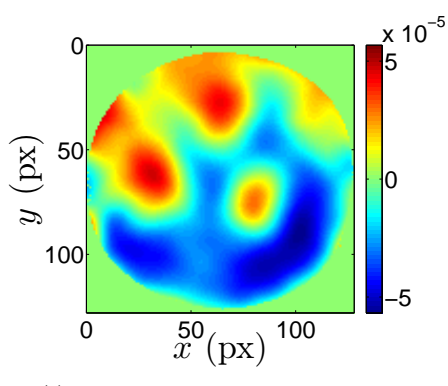

(i) $\Delta T=21.75^{\circ} \mathrm{C}, R a=1745$

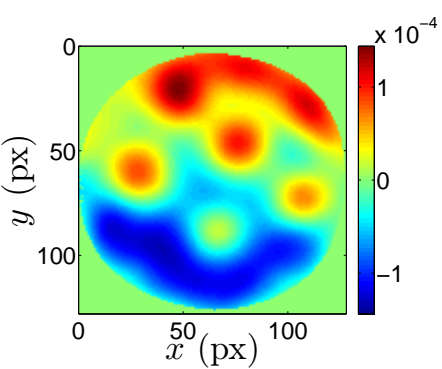

(j) $\Delta T=26.4^{\circ} \mathrm{C}, R a=2119$

$0.2 \%$ of Xanthan gum solution

Figure 8: Vertical velocity $V_{z}(\mathrm{~m} / \mathrm{s})$ in the $(O, x, y)$ plane at the onset of convection for the different Xanthan solutions. (a)-(b) : $0.1 \%$, (c)-(d) : $0.15 \%$, (e)-(f) $: 0.18 \%$ and (g)-(h) $: 0.2 \%$ 


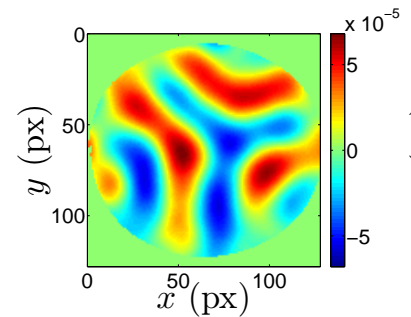

(a) $\Delta T=5^{\circ} \mathrm{C}, R a=2302.6$

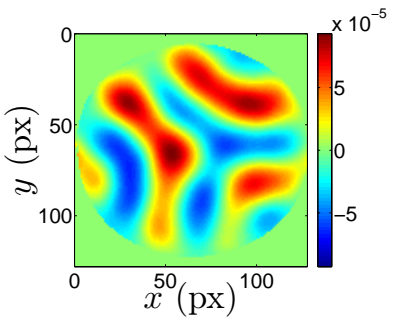

(b) $\Delta T=6^{\circ} \mathrm{C}, R a=2763.1$

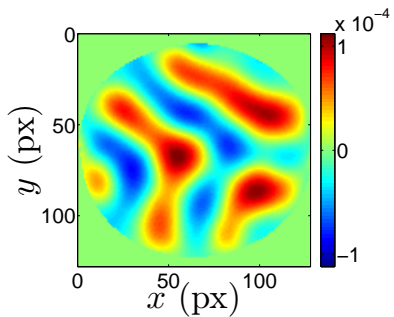

(c) $\Delta T=7.5^{\circ} \mathrm{C}, \mathrm{Ra}=$ 3453.8

Figure 9: Vertical velocity $V_{z}(\mathrm{~m} / \mathrm{s})$ in the $(O, x, y)$ plane with increasing $R a$ values for the Xanthan solution $0.1 \%$

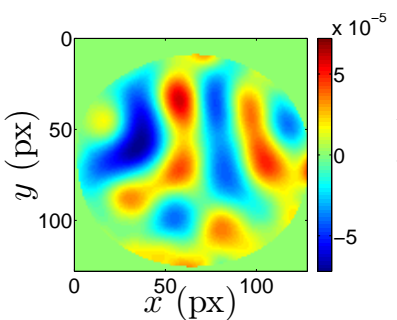

(a) $\Delta T=8.9^{\circ} \mathrm{C}, \mathrm{Ra}=2430$

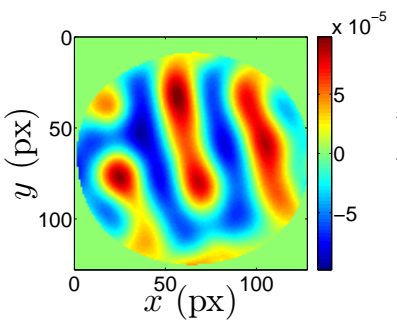

(d) $\Delta T=14.25^{\circ} \mathrm{C}, R a=(\mathrm{e}) \Delta T=15.2^{\circ} \mathrm{C}, R a=4149$ 3890

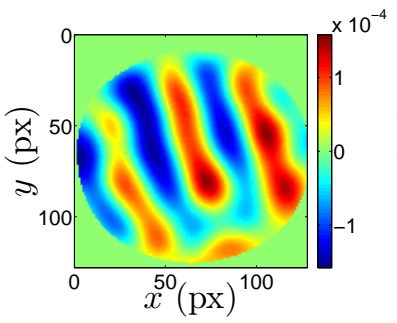

(g) $\Delta T=20.5^{\circ} \mathrm{C}, R a=5596$

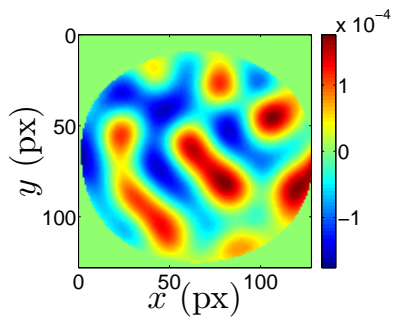

(h) $\Delta T=21.5^{\circ} \mathrm{C}, R a=5869$

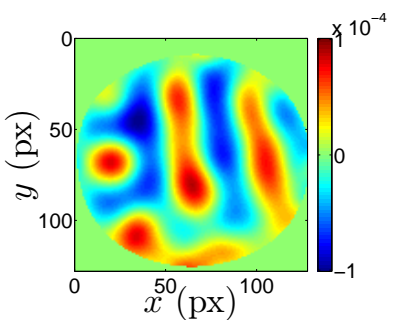

(b) $\Delta T=10.5^{\circ} \mathrm{C}, R a=2866 \quad$ (c) $\Delta T=12.4^{\circ} \mathrm{C}, R a=3385$
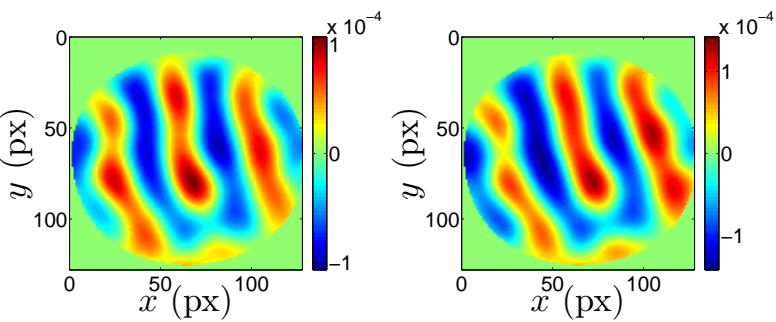

(f) $\Delta T=19.9^{\circ} \mathrm{C}, R a=5432$

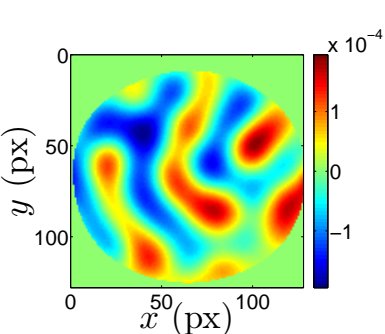

Figure 10: Vertical velocity $V_{z}(\mathrm{~m} / \mathrm{s})$ in the $(O, x, y)$ plane with increasing $R a$ values for the Xanthan solution $0.15 \%$ 

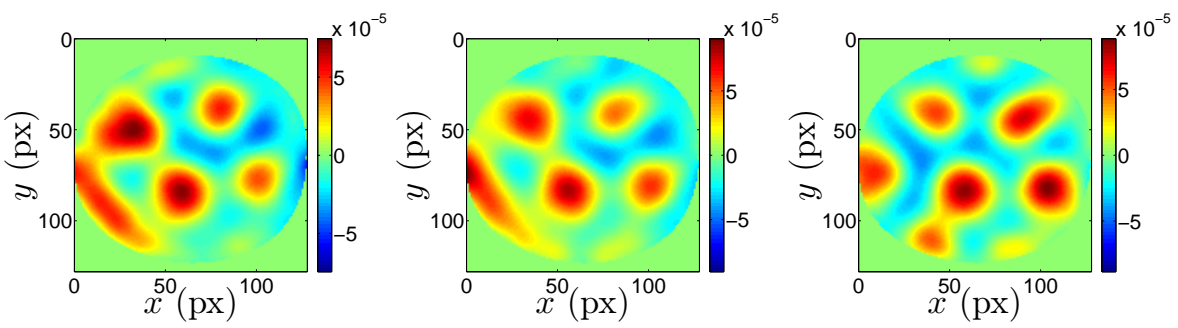

(a) $\Delta T=13.8^{\circ} \mathrm{C}, R a=2374$ (b) $\Delta T=14.25^{\circ} \mathrm{C}, R a=$ (c) $\Delta T=16.1^{\circ} \mathrm{C}, R a=2770$
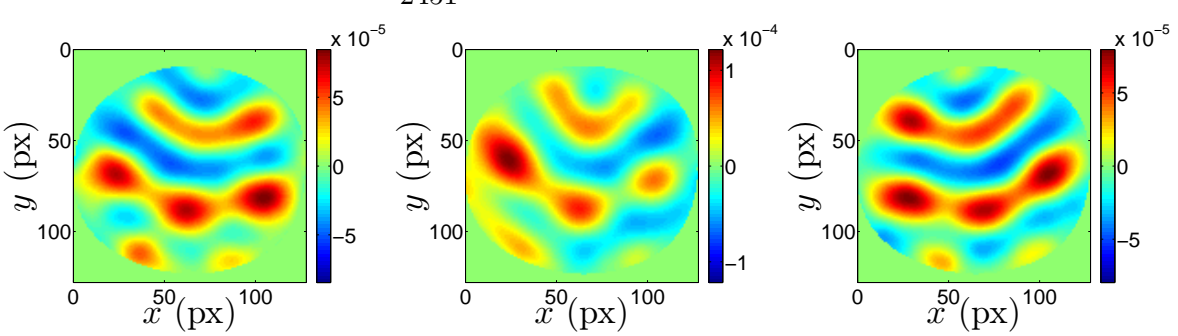

(d) $\Delta T=16.5^{\circ} \mathrm{C}, R a=2839$

(e) $\Delta T=17^{\circ} \mathrm{C}, R a=2925$

(f) $\Delta T=17.6^{\circ} \mathrm{C}, R a=3028$

Figure 11: Vertical velocity $V_{z}(\mathrm{~m} / \mathrm{s})$ in the $(O, x, y)$ plane with increasing $R a$ values for the Xanthan solution $0.18 \%$
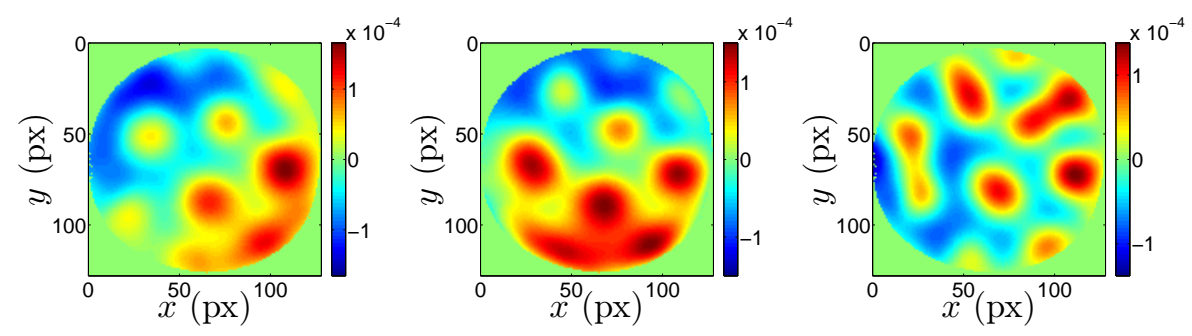

(a) $\Delta T=27.45^{\circ} \mathrm{C}, R a=$ (b) $\Delta T=28.95^{\circ} \mathrm{C}, R a=$ (c) $\Delta T=31.95^{\circ} \mathrm{C}, R a=$ 2203 2323
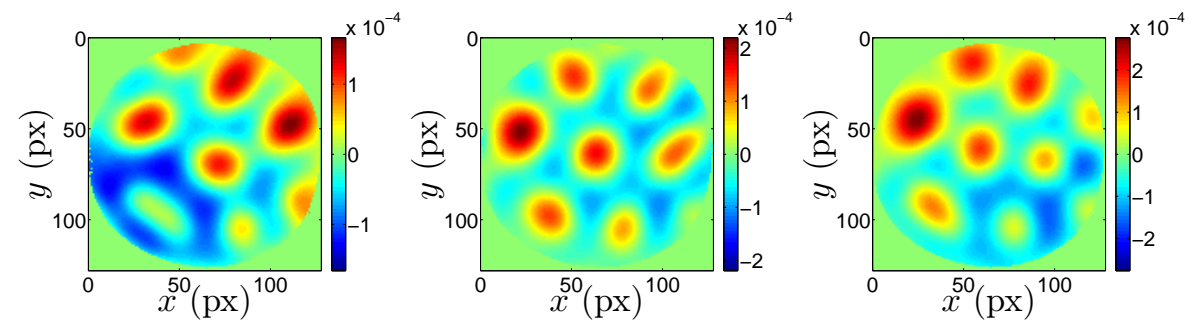

(d) $\Delta T=32.7^{\circ} \mathrm{C}, R a=2624$ (e) $\Delta T=34.75^{\circ} \mathrm{C}, R a=$ (f) $\Delta T=36^{\circ} \mathrm{C}, R a=2889$ 2789

Figure 12: Vertical velocity $V_{z}(\mathrm{~m} / \mathrm{s})$ in the $(O, x, y)$ plane with increasing $R a$ values for the Xanthan solution $0.2 \%$ 


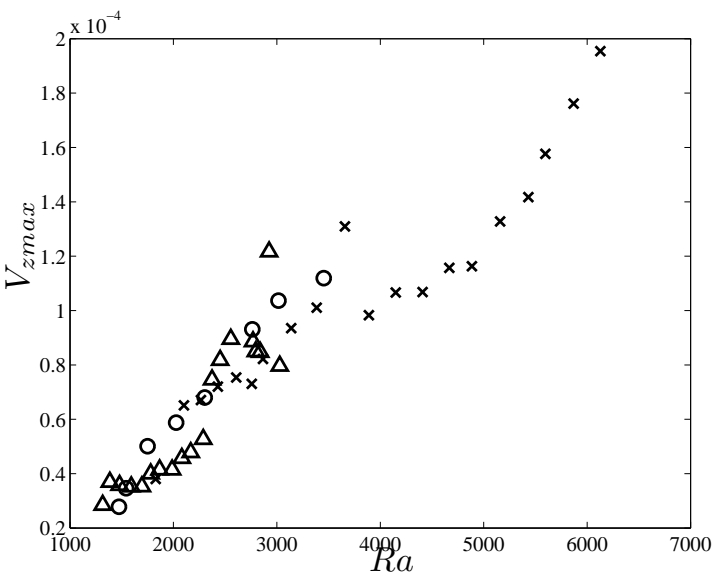

(a) $V_{z \max }(\mathrm{m} / \mathrm{s})$

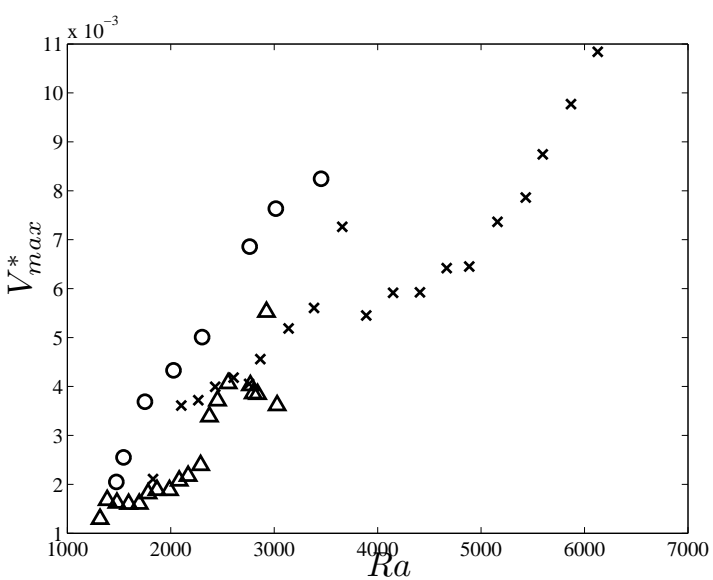

(b) Dimensionless maximal velocity $V_{\max }^{*}$

Figure 13: Maximal velocity values (a) $V_{z \max }(\mathrm{m} / \mathrm{s})$, (b) $V_{\max }^{*}$ as a function of $R a$ for the Xanthan solutions : $\circ: 0.1 \%, \times: 0.15 \%, \Delta: 0.18 \%$ 

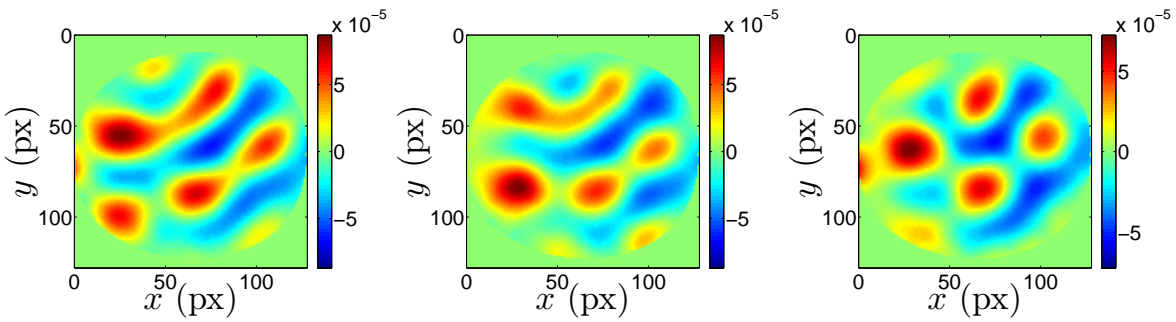

(a) $\Delta T=16.5^{\circ} \mathrm{C}, R a=2839$ (b) $\Delta T=15.55^{\circ} \mathrm{C}, R a=$ (c) $\Delta T=14.4^{\circ} \mathrm{C}, R a=2478$ 2675
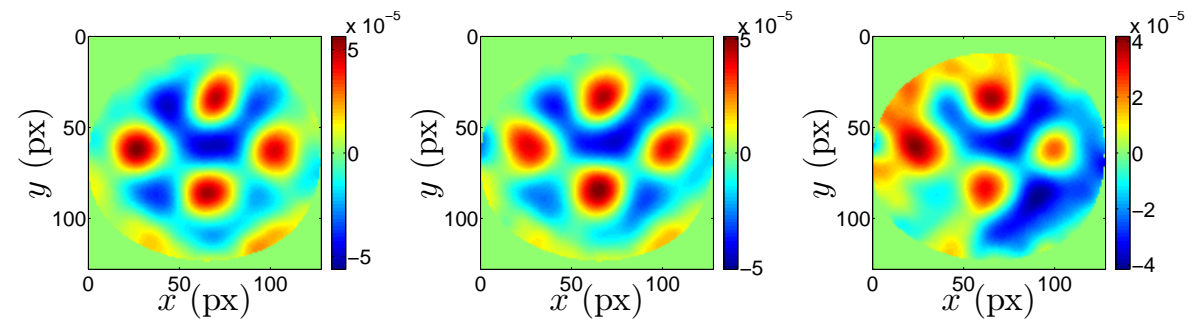

(d) $\Delta T=13.25^{\circ} \mathrm{C}, R a=$ (e) $\Delta T=12.35^{\circ} \mathrm{C}, R a=$ (f) $\Delta T=11.5^{\circ} \mathrm{C}, R a=1979$ 2280 2125

Figure 14: Vertical velocity $V_{z}(\mathrm{~m} / \mathrm{s})$ in the $(O, x, y)$ plane with decreasing $R a$ values for the Xanthan solution $0.18 \%$ 


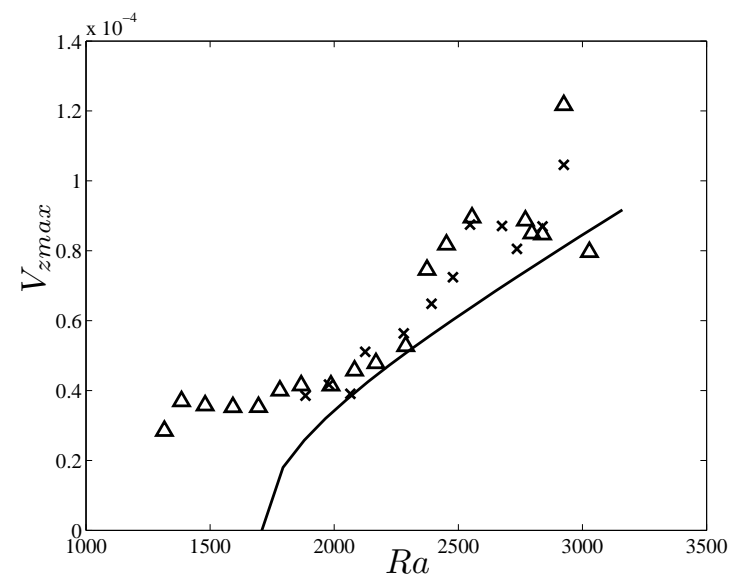

(a) $V_{z \max }(\mathrm{m} / \mathrm{s})$

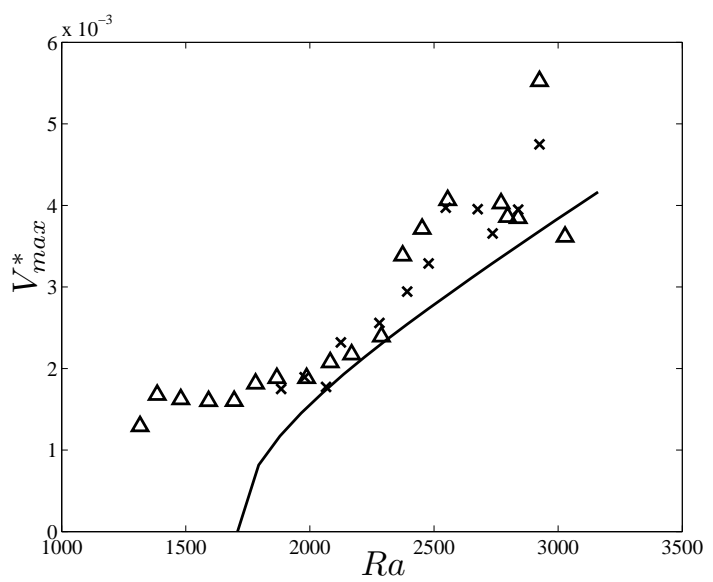

(b) Dimensionless maximal velocity $V_{\max }^{*}$

Figure 15: Maximal velocity values (a) $V_{z \max }(\mathrm{m} / \mathrm{s})$, (b) $V_{\max }^{*}$ as a function of $R a$ for the $0.18 \%$ Xanthan solutions - Open triangles : increasing $R a$, Full triangles : decreasing $R a$, straight line : theoretical result 

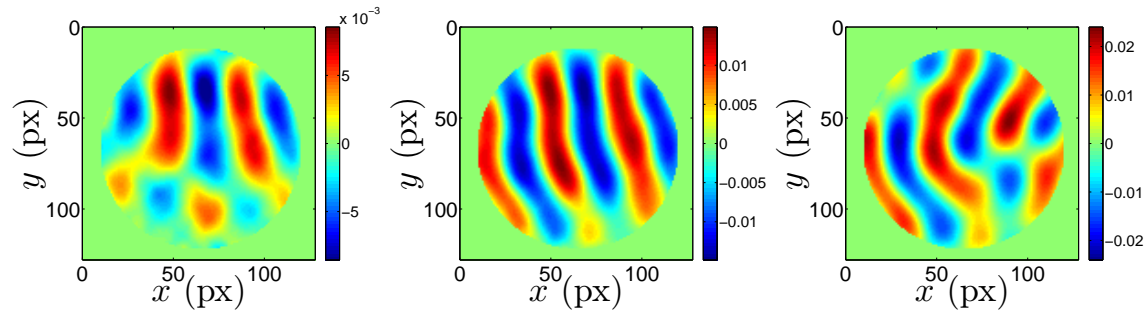

(a) $\Delta T=8.9^{\circ} \mathrm{C}, R a=2430$ (b) $\Delta T=15.2^{\circ} \mathrm{C}, R a=$ (c) $\Delta T=22.5^{\circ} \mathrm{C}, R a=$ 4149 6128

Figure 16: $\dot{\gamma}_{x z}\left(\mathrm{~s}^{-1}\right)$ in the $(O, x, y)$ plane with increasing $R a$ values for the $0.15 \%$ Xanthan solution

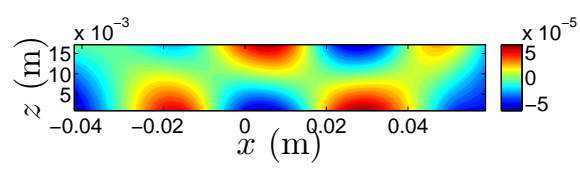

(a) $V_{x}(\mathrm{~m} / \mathrm{s})$

$\Delta T=8.9^{\circ} \mathrm{C}, R a=2430$

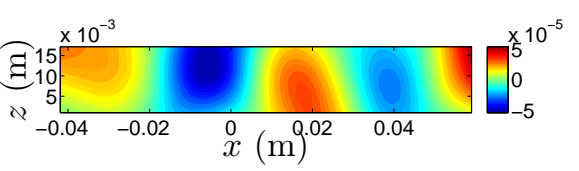

(b) $V_{z}(\mathrm{~m} / \mathrm{s})$

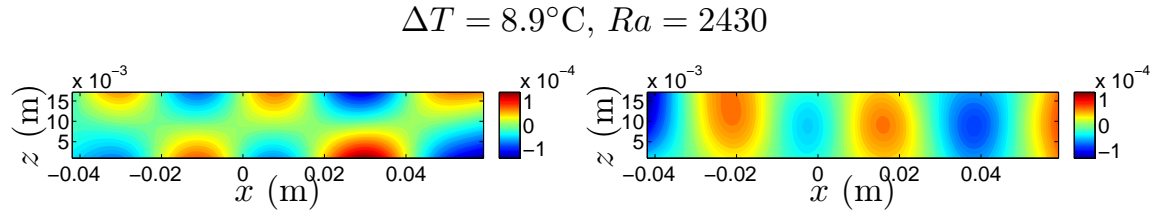

(c) $V_{x}(\mathrm{~m} / \mathrm{s})$

(d) $V_{z}(\mathrm{~m} / \mathrm{s})$

$$
\Delta T=15.2^{\circ} \mathrm{C}, R a=4149
$$

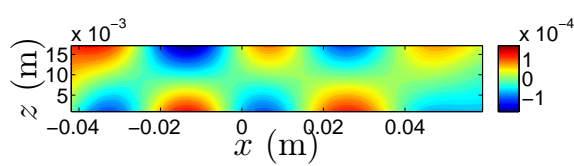

(e) $V_{x}(\mathrm{~m} / \mathrm{s})$

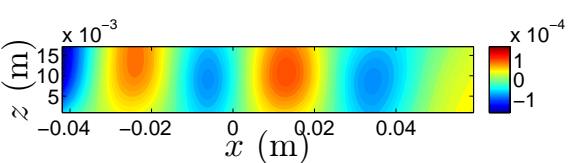

(f) $V_{z}(\mathrm{~m} / \mathrm{s})$

$$
\Delta T=22.5^{\circ} \mathrm{C}, R a=6128
$$

Figure 17: Velocity maps in terms of horizontal velocity $V_{x}$ (left) and vertical velocity $V_{z}$ (right) in the $(O, x, z)$ plane with increasing $R a$ values for the Xanthan solution $0.15 \%$ 


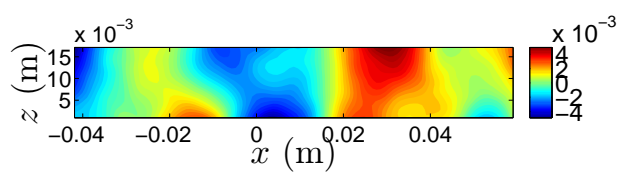

(a) $\Delta T=8.9^{\circ} \mathrm{C}, R a=2430$

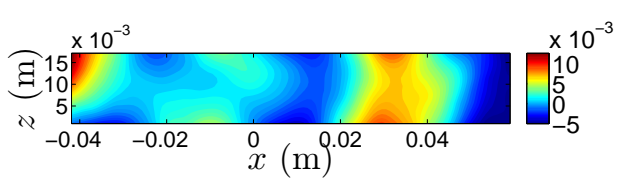

(b) $\Delta T=15.2^{\circ} \mathrm{C}, \mathrm{Ra}=4149$

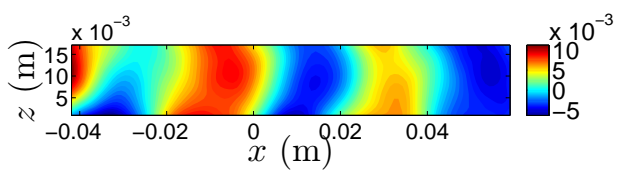

(c) $\Delta T=22.5^{\circ} \mathrm{C}, R a=6128$

Figure 18: Shear rate $\dot{\gamma}_{x z}\left(\mathrm{~s}^{-1}\right)$ component in the $(O, x, z)$ plane with increasing $R a$ values for the Xanthan solution $0.15 \%$ 